\title{
NUMERICAL STUDY AND DESIGN METHOD OF HIGH STRENGTH STEEL WELDED BOX COLUMNS
}

\author{
Yong-Jun Lin ${ }^{1}$, Kai-Qi Liu ${ }^{1}$, Tian-Ji Li ${ }^{2}$ and Yi Zhou*, \\ ${ }^{1}$ School of Civil Engineering, Southwest Jiaotong University, 999 Xi' an road, Chengdu, Sichuan Province, China \\ ${ }^{2}$ Shanghai Construction No.5 (Group) Co., Ltd., 1000 Cao yang road, Shanghai, China \\ *(Corresponding author: E-mail: suzhouzhouyi@switu.edu.cn)
}

\section{A B S T RA C T}

In this paper, the buckling strength of HSS welded box columns was studied by means of numerical study, and the results were used to verify the applicability of provisions of buckling design in the current design codes and provide design recommendations. Fiber models were established taking into account for the effects of residual stress and geometric imperfection. Through the validation against the experimental results, these fiber models showed excellent capability of replicating the key test results, including buckling strengths and load-lateral deflection histories. Then a comprehensive parametric analysis was conducted to reveal the effects of steel grade and width to thickness ratio on column curves. The fiber model results were then compared with the design buckling strength factors from the current designs such as GB50017-2017, Eurocode 3 and ANSI/AISC 360-10. The comparison showed that the design codes could provide satisfactory accuracy in predicting buckling strength of HSS welded box columns by properly selecting columns curves. Furthermore, by updating the coefficients in the three current design codes, new column curves were proposed, which take the effects of yield strength and width-thickness ratio into consideration. The new column curves were proved to be able to predict the buckling strength with better accuracy and could facilitate the design of HSS welded box columns with different steel grades and width to thickness ratios.

\section{A R T I C L E H I S T O R Y}

$\begin{array}{ll}\text { Received: } & \text { 19 April } 2020 \\ \text { Revised: } & \text { 29 December } 2020 \\ \text { Accepted: } & \text { 29 December } 2020\end{array}$

\section{K E Y W O R D S}

High strength steel;

Welded box columns;

Global buckling;

Fiber model;

Column curve

\section{Introduction}

High strength steels (HSS) have yield strength more than 460MPa, which are prevailed in China and abroad. The GJ steel, as a typical high performance HSS, is created in China and increasingly applied in constructions [1-5]. In civil engineering, the commonly used steel grades for HSS columns include S460, S550, S690, S800 and S960 [6-10]. However, the applicability of current design codes in many countries is limited in the scope of normal strength steel (NSS) structures. For example, the Chinese code GB50017-2017 is not suitable for steel grades higher than S420 (420MPa) [11]. Though Eurocode 3 and ANSI/AISC 360-10 (2010) allow the use of HSS up to S700 (700 MPa) and A514 (690 MPa), the column curves in the design codes are on the basis of experiments and theoretical derivations of NSS with nominal yield strength from $235 \mathrm{MPa}$ to $345 \mathrm{MPa}$ [12-13].

In recent years, a series of axial compression experiments on columns made of HSS and GJ steel had been reported, where the main results include buckling capacity, typical failure mode, global and local buckling behaviors. It was concluded that the overall buckling behavior of HSS columns may be characterized differently from NSS columns due to different material properties and manufacturing processes. Furthermore, several researchers conducted experiments on residual stress and investigated its influence on overall buckling of HSS columns. The results indicated that the effects of initial geometric imperfections and residual stresses on buckling strength become less significant with increasing yield strength [14-20].

However, it was found that the existing researches are limited in conducting experiments on few specimens with one or several steel grades and sectional dimensions. Thus the column curves and design recommendations based on the experiments are unable to take material steel grade and sectional width to thickness ratio into consideration. As a result, the current design codes, such as Chinese code GB50017-2017, Eurocode 3 and American code ANSI/AISC 360-10 have not included these experimental results into provisions, making them not applicable to the buckling design of HSS columns [11-13].

This paper presented a numerical study in order to investigate the effect of material properties and sectional dimensions on buckling strength of HSS welded box columns. The buckling strengths of 1105 HSS welded box columns were obtained by means of fiber model and compared against the predictions of GB50017-2017, Eurocode 3 and ANSI/AISC 360-10. Based on the comparison, several recommendations were proposed for the design of HSS welded box columns subject to axial compression using the current codes. Furthermore, by updating the coefficients in the provisions, new column curves were proposed, which are described as functions of width to thickness ratio and nominal yield strength. The newly proposed column curves were proved to have better accuracy in predicting buckling strength of HSS welded box columns and could provide a unified design method for HSS welded box columns with different sectional dimensions and yield strength from 460MPa to $960 \mathrm{MPa}$.

\section{Recent experimental results}

On the basis of the literature review on previous axial compression experiments, several databases were collected.

Wang et al. and Li et al. investigated the buckling performance of S460 and S690 welded box columns with different slenderness and width to thickness ratios and reported the corresponding load-deflection curves and load-strain curves [21-23].

Ban et al. tested a series of S960 welded box columns with the same sectional dimension but different slenderness to buckling and proposed design recommendations for buckling design using ANSI/AISC 360-10, Eurocode 3 and GB50017-2003 codes [17]. Furthermore, Ban et al. conducted experiments on welded box and I-shaped columns made of S460 steel, where the boundary condition of the specimens was not perfect pin-end support and the initial rotational stiffness of the hinges was measured [24].

Nie et al., Kang et al., Zhou and Xue et al. carried out experiments on GJ welded box columns, where the main results include buckling strengths, load-deflection curves and load-strain curves [1, 4, 5, 25]. According to the results, several supplements for ANSI/AISC 360-10, Eurocode 3 and GB50017-2003 codes were proposed.

Table 1 lists the dimensions and the buckling strengths of the specimens in the aforementioned experiments, where $B$ is the sectional dimension, $t$ is the plate thickness, $L$ is the length, $v_{e}$ is the initial loading eccentricity, $v_{0}$ is the initial bending, $f_{y}$ is the yield strength of steel, $E$ is the Elastic modules and $P_{u}$ is the buckling strength. 
Table 1

Specimens in collected database

\begin{tabular}{|c|c|c|c|c|c|c|c|c|c|c|}
\hline HSS type & Reference & Specimen & $\begin{array}{c}B \\
(\mathrm{~mm})\end{array}$ & $\begin{array}{c}t \\
(\mathrm{~mm})\end{array}$ & $\begin{array}{c}L \\
(\mathrm{~mm})\end{array}$ & $\begin{array}{c}v_{e} \\
(\mathrm{~mm})\end{array}$ & $\begin{array}{c}v_{0} \\
(\mathrm{~mm})\end{array}$ & $\begin{array}{c}f_{y} \\
(\mathrm{MPa})\end{array}$ & $\begin{array}{c}E \\
(\mathrm{GPa})\end{array}$ & $\begin{array}{c}P_{u} \\
(\mathrm{kN})\end{array}$ \\
\hline \multirow{14}{*}{ Conventional } & \multirow{6}{*}{ Wang et al. [21] } & B-8-80-1 & 110 & 11.40 & 3320 & 0.50 & -3.50 & 506 & 208 & 1122 \\
\hline & & B-8-80-2 & 112 & 11.49 & 3260 & -0.9 & 1.50 & 506 & 208 & 1473 \\
\hline & & B-12-55-1 & 156 & 11.43 & 3260 & 1.90 & 3.00 & 506 & 208 & 2591 \\
\hline & & B-12-55-2 & 156 & 11.42 & 3260 & -1.80 & -2.00 & 506 & 208 & 2436 \\
\hline & & B-18-38-1 & 220 & 11.46 & 3260 & -0.60 & 3.00 & 506 & 208 & 3774 \\
\hline & & B-18-38-2 & 221 & 11.46 & 3260 & 1.4 & 2.00 & 506 & 208 & 4010 \\
\hline & \multirow{5}{*}{ Li et al. [22-23] } & B-30-2 & 236 & 16.10 & 2812 & 2.40 & 2.50 & 772 & 233 & 9751 \\
\hline & & B-50-1 & 192 & 16.02 & 3610 & 0.10 & -1.00 & 772 & 233 & 6444 \\
\hline & & B-50-2 & 193 & 16.02 & 3612 & -0.80 & -1.50 & 772 & 233 & 7180 \\
\hline & & B-70-1 & 141 & 16.07 & 3610 & -0.80 & -2.00 & 772 & 233 & 3528 \\
\hline & & B-70-2 & 140 & 16.08 & 3609 & 0 & -1.50 & 772 & 233 & 2897 \\
\hline & \multirow{3}{*}{ Ban et al. [17] } & B1-960 & 143 & 13.99 & 1879 & 26.19 & -0.31 & 973 & 208 & 3779 \\
\hline & & B2-960 & 142 & 13.94 & 2880 & -1.97 & -1.16 & 973 & 208 & 4064 \\
\hline & & B3-960 & 142 & 13.92 & 4382 & 3.45 & -2.63 & 973 & 208 & 2193 \\
\hline \multirow{24}{*}{ GJ } & \multirow{9}{*}{ Xue et al. [25] } & $460 \mathrm{~B} 50-150 \times 12$ & 155 & 12.46 & 3118 & 0 & 4.31 & 492 & 210 & 2508 \\
\hline & & $460 \mathrm{~B} 70-100 \times 12$ & 105 & 12.35 & 2828 & 0 & 3.05 & 492 & 210 & 1245 \\
\hline & & $550 \mathrm{~B} 110-75 \times 12$ & 77 & 12.51 & 3170 & 0 & 4.43 & 635 & 208 & 451 \\
\hline & & $550 \mathrm{~B} 30-100 \times 12$ & 101 & 12.60 & 1378 & 0 & 2.42 & 635 & 208 & 2057 \\
\hline & & $550 \mathrm{~B} 30-150 \times 12$ & 153 & 12.82 & 1987 & 0 & 0.95 & 635 & 208 & 4117 \\
\hline & & $550 \mathrm{~B} 50-100 \times 12$ & 102 & 12.60 & 2103 & 0 & 2.01 & 635 & 208 & 1900 \\
\hline & & $550 \mathrm{~B} 50-150 \times 12$ & 153 & 12.82 & 3118 & 0 & 0.82 & 635 & 208 & 3560 \\
\hline & & $550 \mathrm{~B} 70-100 \times 12$ & 102 & 12.60 & 2828 & 0 & 4.47 & 635 & 208 & 1177 \\
\hline & & $690 \mathrm{~B} 50-100 \times 12$ & 106 & 12.61 & 2103 & 0 & 0.78 & 727 & 211 & 2514 \\
\hline & \multirow{4}{*}{ Kang et al. [4] } & B-120-12 & 120 & 12.23 & 3493 & 2.34 & -1.22 & 546 & 209 & 1635 \\
\hline & & B-168-12 & 168 & 12.45 & 4111 & 1.19 & -2.44 & 546 & 209 & 2740 \\
\hline & & B-264-12 & 264 & 12.21 & 3684 & 0.88 & -3.12 & 546 & 209 & 5852 \\
\hline & & B-175-25 & 176 & 21.53 & 5323 & 2.74 & -0.12 & 473 & 209 & 3453 \\
\hline & \multirow{3}{*}{ Zhou [5] } & B-200-25 & 201 & 25.42 & 5154 & 3.42 & -1.37 & 473 & 208 & 4511 \\
\hline & & B- $225-25$ & 226 & 25.33 & 4704 & 2.41 & -1.75 & 473 & 208 & 6710 \\
\hline & & B-250-25 & 251 & 25.32 & 3965 & 2.37 & -2.25 & 473 & 208 & 8105 \\
\hline & \multirow{8}{*}{ Nie et al. [1] } & B-120-45 & 121 & 12.54 & 3392 & 48.10 & -2.58 & 557 & 208 & 862 \\
\hline & & B-120-75 & 121 & 12.60 & 3391 & 79.40 & 1.16 & 557 & 208 & 643 \\
\hline & & B-168-30 & 169 & 12.61 & 4009 & 28.60 & -1.22 & 557 & 208 & 2004 \\
\hline & & B-168-60 & 168 & 12.63 & 4009 & 58.80 & 1.51 & 557 & 208 & 1470 \\
\hline & & B-216-45 & 217 & 12.57 & 4072 & 44.60 & -1.14 & 557 & 208 & 2881 \\
\hline & & B-216-75 & 217 & 12.55 & 4075 & 74.00 & -3.61 & 557 & 208 & 2241 \\
\hline & & B-264-30 & 264 & 12.59 & 3583 & 30.6 & -0.96 & 557 & 208 & 4749 \\
\hline & & B-264-60 & 265 & 12.63 & 3582 & 58.80 & 1.67 & 557 & 208 & 3900 \\
\hline
\end{tabular}

\section{Fiber model}

\subsection{Assumptions}

According to the previous researches, the following assumptions are made for the fiber model [26-27]:

(1) A plane cross section remains plane after deformation.

(2) The deformation of structure consists with half-sinusoid.

(3) All members are assumed to be fully compact and adequately braced, thus local buckling and lateral torsional buckling are not considered.

(4) The influence of shear deformation is not considered.

\subsection{Calculation method}

The whole mid-span cross section is meshed into rectangular fibers for the preparation of numerical calculation, as shown in Fig. 1, where $P$ is the load position of axial force and $e_{0}$ is the initial geometric imperfection to the mid-span section, which can be calculated by Eq. (1). Herein, each fiber is represented by its area and coordinate location corresponding to its centroid. The residual stresses are assigned directly to fibers as the initial stresses and the properties of the cross-section can be evaluated at each step of analysis [26]. 


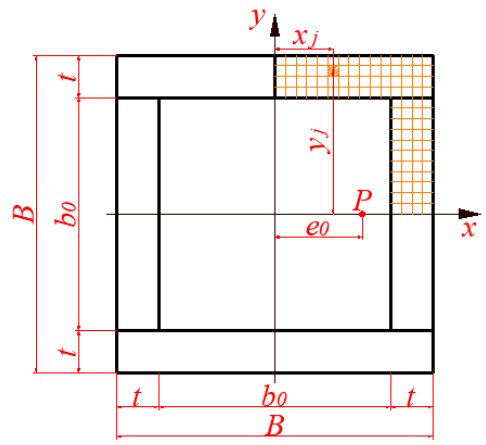

Fig. 1 Mesh fibers and sectional dimensions

$e_{0}=\left|v_{e}+v_{0}\right|$

According to the assumption 2, the lateral deflection of axial compression member can be calculated by:

$u_{i}=u_{m} \sin \frac{\pi}{L} z$

where, $u_{i}$ is the lateral displacement of section number $i, u_{m}$ is the lateral displacement of mid-span section and $z$ is the distance from the $i$ section to the top end of the column.

The curvature of the mid-span section, $\phi_{m}$, is:

$\phi_{m}=u_{m} \frac{\pi^{2}}{L^{2}}$

In the mid-span cross section, the coordinate of the fiber number $j$ can be expressed as $\left(x_{j}, y_{j}\right)$, and the strain $\varepsilon_{j}$ of the fiber is given by:

$\varepsilon_{j}=\varepsilon_{c}+\phi_{m} x_{j}+\sigma_{r s j} / E$

where, $\varepsilon_{c}$ is the centroid strain of the section, $\sigma_{r s j}$ is the residual stress of fiber number $j$ and $E$ is the elastic module.

Then the stress of the fiber number $j$ can be calculated according to the constitutive relation:

$\sigma_{j}=f\left(\varepsilon_{j}\right)$

where the symbol ' $f()$ ' represents the constitutive function of steel, as shown in Fig. 2 and defined by Eq. (6).

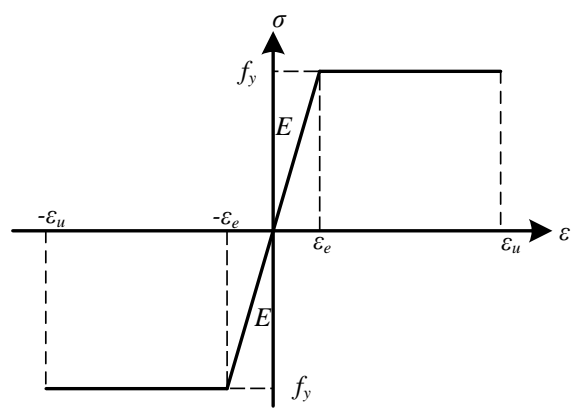

Fig. 2 Constitutive function of steel applied in fiber model

$\sigma=\left\{\begin{array}{cc}f_{y} & \varepsilon_{e} \leq \varepsilon<\varepsilon_{u} \\ E \varepsilon & -\varepsilon_{e} \leq \varepsilon<\varepsilon_{e} \\ -f_{y} & -\varepsilon_{u} \leq \varepsilon<-\varepsilon_{e}\end{array}\right.$

where, $\sigma$ is the stress, $\varepsilon_{e}$ is the elastic strain, $\varepsilon_{u}$ is the ultimate strain.

Then, the internal axial force $N_{i n}$ and bending moment $M_{i n}$ can be calculated as:
$M_{i n}=\sum_{j=1}^{k} \sigma_{j} A_{j} x_{j}$

$N_{i n}=\sum_{j=1}^{k} \sigma_{j} A_{j}$

where $k$ is the total number of fibers.

\subsection{Residual stres}

The residual stress has a strong influence on the buckling behavior of axial compression members, and the fiber models employing different residual models will result in different buckling strengths [17, 20, 28, 29]. A unified residual model suitable for HSS welded box columns of comprehensive steel grades and sectional dimensions was proposed by Ban et al., which could be further employed in the current numerical research $[17,20]$. The shape of the unified model is presented in Fig. 3 and the major parameters, such as width of tensile and compressive stress areas, magnitude of tensile stress and the self-balance conditions are listed in Tables 2-3.

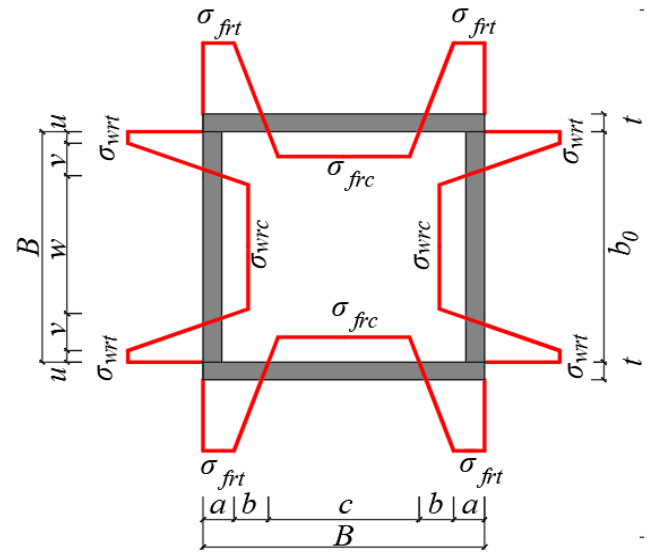

Fig. 3 Unified residual stress model

Table 2

Magnitude parameters of the unified residual stress model

\begin{tabular}{cc|c}
\hline \multicolumn{2}{c|}{$\sigma_{f r t,} \sigma_{w r t}$} & $\sigma_{f r c}, \sigma_{w r c}$ \\
\hline $460 \mathrm{MPa} \leq f_{y} \leq 690 \mathrm{MPa}$ & $460 \mathrm{MPa}$ & $\sigma_{r c}=-95-\frac{1450}{h_{0} / t}-\frac{270}{t}$ \\
$f_{y} \geq 690 \mathrm{MPa}$ & $690 \mathrm{MPa}$ & $-f_{y} \leq \sigma_{r c} \leq-0.1 f_{y}$ \\
\hline
\end{tabular}

Table 3

Location parameters of the unified residual stress model

\begin{tabular}{|c|c|c|c|}
\hline$a$ & $u$ & $b, c$ & $v, w$ \\
\hline \multirow[t]{2}{*}{$t+h_{0} / 10$} & $t$ & $\iint_{A_{f}} \sigma_{r s} \cdot d A=0$ & $\iint_{A_{w}} \sigma_{r s} \cdot d A=0$ \\
\hline & & $2(a+b)+c=D$ & $2(u+v)+w=b_{0}$ \\
\hline
\end{tabular}

In Table $3, A_{f}$ is the area of flange, $A_{w}$ is the area of web and $\sigma_{r s}$ is the residual stress.

\subsection{Equilibrium and calculation process}

According to the assumption 4, the equilibrium of the mid-span section subject to axial compression and bending moment can be defined as:

$M_{i n}-N_{i n}\left(e_{0}+u_{m}\right)=0$

where $u_{m}$ is the deflection in the mid-span section oriented from bending moment.

Since the axial force $N_{i n}$ is coupled with the bending moment $M_{i n}$, the mid-span deflection $u_{m}$ and the mid-span curvature $\phi_{m}$, an iterative method should be employed to find the solution of Eq. (9). Giving a specific mid-span curvature $\phi_{m}$, the processes of iteration aiming to find the axial force $N_{\text {in }}$ 
corresponding to the $\phi_{m}$ and satisfying the equilibrium is presented in Fig. 4 [27].

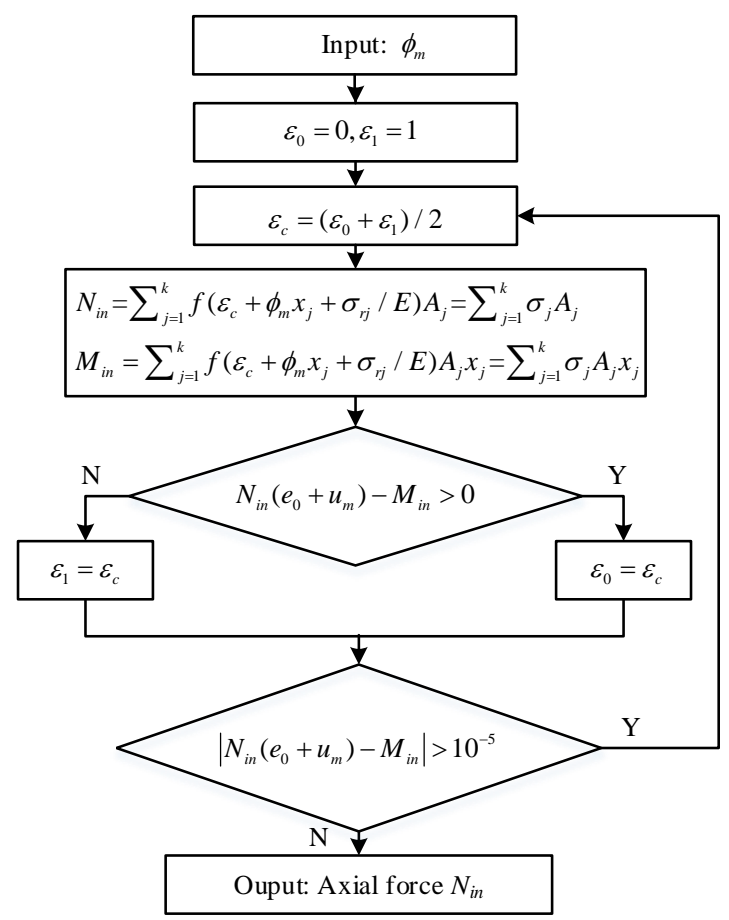

Fig. 4 Flowchart for iterative method

\subsection{Calculation process}

The calculation process includes the three steps:

a) Give a specific mid-span curvature $\phi$;

b) Calculate the deflection of the mid-span section $u_{m}$ subject to the given $\phi_{m}$ according to Eq. (10);

c) Calculate axial load using the iterative strategy presented in Fig. 4.

The steps are repeated until the curvature of the mid-span section reaches a preset value and the whole load-deflection curve can be obtained. Then, the buckling strength can be set as the peak load. The specific processes are shown in Fig. 5.

$u_{m}=\frac{L^{2}}{\pi^{2}} \phi_{m}$

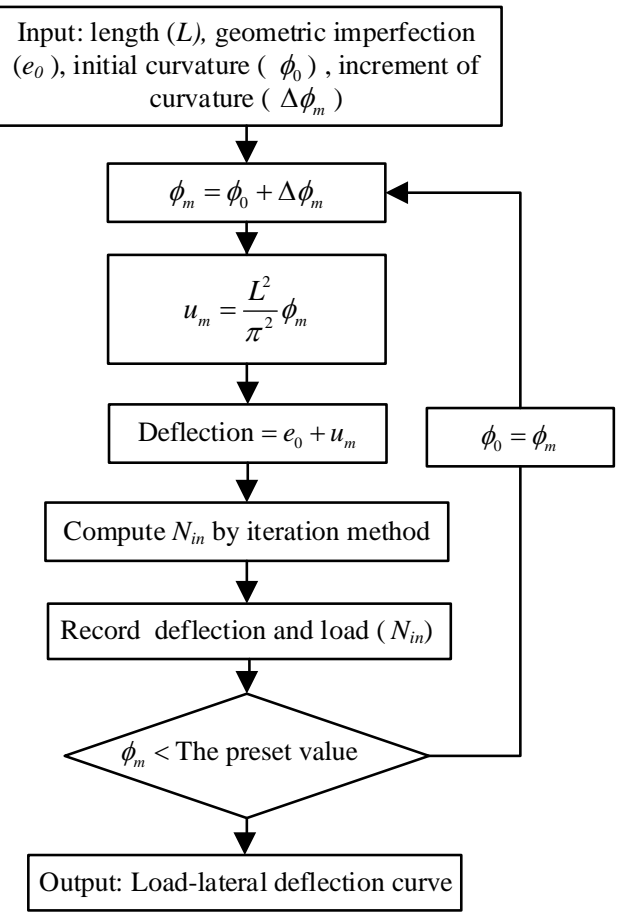

Fig. 5 Flowchart for calculation process

\section{Model validation}

To verify the accuracy, efficiency and versatility of the fiber model, HSS welded box columns under axial compression are analyzed and compared with the test data presented by several scholars. The buckling strengths of fiber models and the buckling strengths of test specimens are compared in Table 4 . It can be seen that the buckling strength ratios range from 0.89 to 1.31 with an average of 1.05. Thus, the fiber models with unified residual stress model are able to capture the buckling strength of HSS welded box columns. The load-deflection curves obtained from the fiber models and test results are shown in Fig. 8. The comparison suggests that the numerical results are in good agreement with test results. Overall, it is concluded that the fiber models are capable of replicating the key test results.

Table 4

Comparison on buckling strength between test results and fiber models

\begin{tabular}{|c|c|c|c|c|}
\hline Reference & Specimen & $\begin{array}{c}\text { Test buckling } \\
\text { strength } \\
(\mathrm{kN})\end{array}$ & $\begin{array}{c}\text { Fiber model } \\
\text { buckling strength } \\
(\mathrm{kN})\end{array}$ & Ratio \\
\hline \multirow{6}{*}{ Wang et al. [21] } & B-8-80-1 & 1122 & 987 & 1.14 \\
\hline & B-8-80-2 & 1473 & 1124 & 1.31 \\
\hline & B-12-55-1 & 2591 & 2220 & 1.17 \\
\hline & B-12-55-2 & 2436 & 2253 & 1.08 \\
\hline & B-18-38-1 & 3774 & 4178 & 0.90 \\
\hline & B-18-38-2 & 4010 & 4122 & 0.97 \\
\hline \multirow{5}{*}{ Li et al. [22-23] } & B-30-2 & 9751 & 8680 & 1.12 \\
\hline & B-50-1 & 6444 & 5675 & 1.14 \\
\hline & B-50-2 & 7180 & 5551 & 1.29 \\
\hline & B-70-1 & 3528 & 3132 & 1.13 \\
\hline & B-70-2 & 2897 & 2825 & 1.03 \\
\hline \multirow{3}{*}{ Ban et al. [17] } & B1-960 & 3779 & 3805 & 0.99 \\
\hline & B2-960 & 4064 & 3806 & 1.07 \\
\hline & B3-960 & 2193 & 2052 & 1.07 \\
\hline \multirow{9}{*}{ Xue et al. [25] } & $460 \mathrm{~B} 50-150 \times 12$ & 2508 & 2379 & 1.05 \\
\hline & $460 \mathrm{~B} 70-100 \times 12$ & 1245 & 1109 & 1.12 \\
\hline & $550 \mathrm{~B} 110-75 \times 12$ & 451 & 413 & 1.09 \\
\hline & $550 \mathrm{~B} 30-100 \times 12$ & 2057 & 2323 & 0.89 \\
\hline & $550 \mathrm{~B} 30-150 \times 12$ & 4117 & 4162 & 0.99 \\
\hline & $550 \mathrm{~B} 50-100 \times 12$ & 1900 & 1794 & 1.06 \\
\hline & $550 \mathrm{~B} 50-150 \times 12$ & 3560 & 3138 & 1.13 \\
\hline & $550 \mathrm{~B} 70-100 \times 12$ & 1177 & 1178 & 1.00 \\
\hline & $690 \mathrm{~B} 50-100 \times 12$ & 2514 & 2009 & 1.25 \\
\hline \multirow{4}{*}{ Kang et al. [4] } & B-120-12 & 1635 & 1384 & 1.18 \\
\hline & B-168-12 & 2740 & 2595 & 1.06 \\
\hline & B-264-12 & 5852 & 6089 & 0.96 \\
\hline & B-175-25 & 3453 & 3269 & 1.06 \\
\hline \multirow{3}{*}{ Zhou [5] } & B-200-25 & 4511 & 4550 & 0.99 \\
\hline & B-225-25 & 6710 & 6786 & 0.99 \\
\hline & B-250-25 & 8105 & 9427 & 0.86 \\
\hline \multirow{8}{*}{ Nie et al. [1] } & B-120-45 & 862 & 826 & 1.04 \\
\hline & B-120-75 & 643 & 659 & 0.98 \\
\hline & B-168-30 & 2004 & 1970 & 1.02 \\
\hline & B-168-60 & 1470 & 1514 & 0.97 \\
\hline & B-216-45 & 2881 & 2966 & 0.97 \\
\hline & B-216-75 & 2241 & 2482 & 0.90 \\
\hline & B-264-30 & 4749 & 4917 & 0.97 \\
\hline & B-264-60 & 3900 & 4084 & 0.96 \\
\hline
\end{tabular}


(a) $550 \mathrm{~B} 70-100 \times 12$

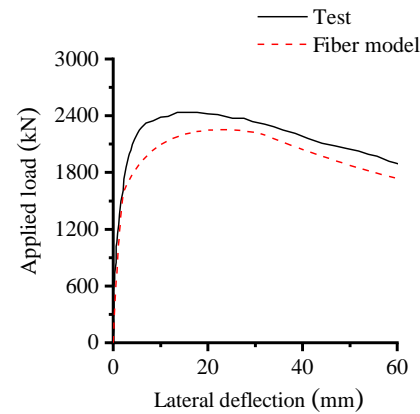

(c) B-12-55-2

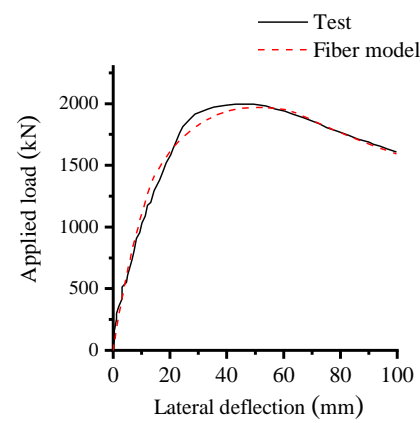

(e) B-168-30

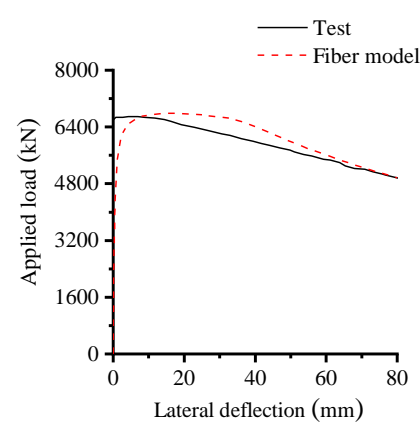

(g) B-225-25

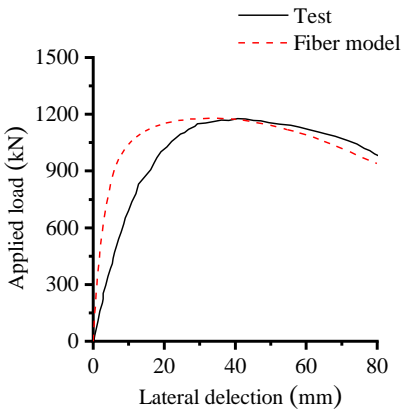

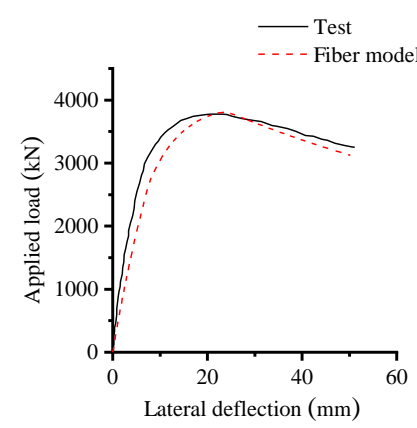

(b) B1-960

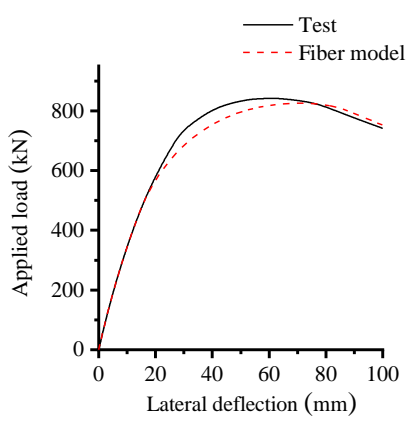

(d) B-120-45

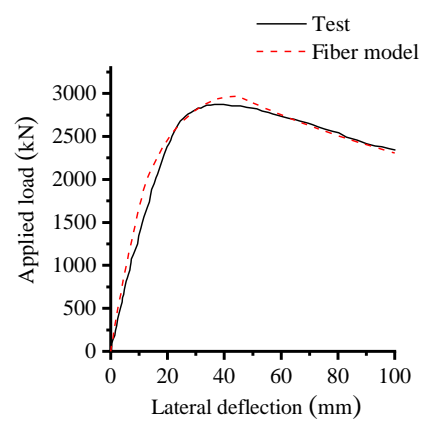

(f) B-216-45

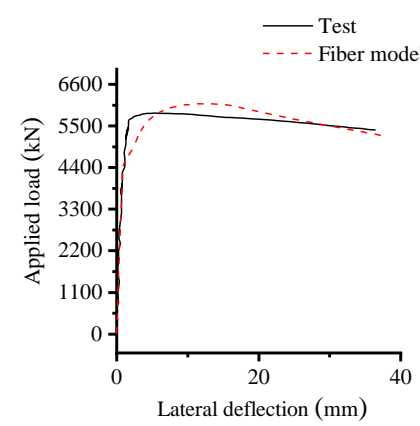

(h) B-264-12
Fig. 6 Comparison on load-deflection curves between test results and fiber model results

\section{Parametric studies and design recommendations}

\subsection{Parametric studies}

Having validated the fiber models against the test results, a series of parametric studies are performed, focusing on steel grades and sectional width to thickness ratios. The sectional dimensions of specimens in the parametric study are listed in Table 5. For each sectional dimension, the slenderness varies from 10 to 130 with an interval of 10 corresponding to non-dimensional slenderness ranging from 0.15 to 3.0. And for each combination of sectional dimension and slenderness, the steel grades include S460, S550, S690, S800 and S960. The initial geometric imperfection is set as $1 \%$ of the specimen length covering unintentional load eccentricities and initial bending [11-13].

The buckling strength factors for each specimen are calculated according to the column curves in the design codes GB50017-2017, Eurocode 3 and ANSI/AISC 360-10. According to GB50017-2017, the curve $\mathrm{c}$ is used to design welded box columns with width to thickness ratios lower than 20 and curve the $\mathrm{b}$ is used to design welded box columns with width to thickness ratios higher than 20. According to Eurocode 3, the curve b is used to design welded box columns with width to thickness ratios higher than 30 and the curve $\mathrm{c}$ is used to design welded box columns with width-thickness ratios lower than 30 . ANSI/AISC 360-10 code employs a single column curve to design all the welded box columns. The corresponding relations of sectional dimensions and design curves are listed in Table 5.

Table 5

Sectional dimensions of fiber models

\begin{tabular}{cccc|ccc}
\hline & & & & \multicolumn{3}{|c}{ Design curve } \\
\cline { 5 - 7 } Section & $B(\mathrm{~mm})$ & $t(\mathrm{~mm})$ & $b$ o/ & & & \\
& & & & GB50017-2017 & Eurocode 3 & ANSI/AISC \\
& & & & & & $360-10$ \\
\hline Sec-B1 & 77 & 13 & 3.92 & Curve b & Curve c & Curve a \\
Sec-B2 & 101 & 13 & 5.77 & Curve b & Curve c & Curve a \\
Sec-B3 & 201 & 25 & 6.04 & Curve b & Curve c & Curve a \\
Sec-B4 & 140 & 16 & 6.75 & Curve b & Curve c & Curve a \\
Sec-B5 & 120 & 12 & 8.00 & Curve b & Curve c & Curve a \\
Sec-B6 & 251 & 25 & 8.04 & Curve b & Curve c & Curve a \\
Sec-B7 & 192 & 16 & 10.00 & Curve b & Curve c & Curve a \\
Sec-B8 & 155 & 12 & 10.92 & Curve b & Curve c & Curve a \\
Sec-B9 & 168 & 12 & 12.00 & Curve b & Curve c & Curve a \\
Sec-B10 & 250 & 11 & 20.73 & Curve c & Curve c & Curve a \\
Sec-B11 & 220 & 10 & 20.00 & Curve c & Curve c & Curve a \\
Sec-B12 & 270 & 12 & 20.50 & Curve c & Curve c & Curve a \\
Sec-B13 & 380 & 14 & 25.14 & Curve c & Curve c & Curve a \\
Sec-B14 & 360 & 12 & 28.00 & Curve c & Curve c & Curve a \\
Sec-B15 & 390 & 12 & 30.50 & Curve c & Curve b & Curve a \\
Sec-B16 & 350 & 10 & 33.00 & Curve c & Curve b & Curve a \\
Sec-B17 & 211 & 6 & 33.17 & Curve c & Curve b & Curve a \\
\hline & & & & & &
\end{tabular}

\subsection{Applicability of current design codes}

In GB 50017-2017 the buckling strength $N_{d}$ of axial compression member is expressed as,

$N_{d}=\varphi A f_{y}$

where $\varphi$ is the buckling strength factor.

When $\lambda_{d} \leq 0.215$,

$\varphi=1-a_{1} \lambda_{d}^{2}$

When $\lambda_{d}>0.215$

$\varphi=\frac{\left(a_{2}+a_{3} \lambda_{d}+\lambda_{d}{ }^{2}\right)-\sqrt{\left(a_{2}+a_{3} \lambda_{d}+\lambda_{d}{ }^{2}\right)^{2}-4 \lambda_{d}^{2}}}{2 \lambda_{d}{ }^{2}}$

where $\lambda_{d}$ is the non-dimensional slenderness, $a_{1}, a_{2}$ and $a_{3}$ are the imperfection factors.

The buckling strength of column in Eurocode 3 is defined as,

$N_{d}=\varphi_{e} A f_{y}$

where $\varphi_{e}$ is the buckling strength factor

When $\lambda_{d} \leq 0.2$

$\varphi_{e}=1$

When $\lambda_{d}>0.2$, 


$$
\varphi_{e}=\frac{1}{0.5\left[1+a_{E}\left(\lambda_{d}-0.2\right)+\lambda_{d}{ }^{2}\right]+\sqrt{\left\{0.5\left[1+a_{E}\left(\lambda_{d}-0.2\right)+\lambda_{d}{ }^{2}\right]\right\}^{2}-\lambda_{d}{ }^{2}}}
$$

where, $a_{E}$ is the imperfection factor.

In ANSI/AISC 360-10, the buckling strength of axial compression member is calculated by Eq. (17).

$N_{d}=\varphi_{c} A f_{y}$

where $\varphi_{c}$ is the buckling strength factor.

When $\lambda_{d} \leq 1.5$,

$\varphi_{c}=a_{A N}^{\lambda_{n}^{2}}$

When $\lambda_{d}>1.5$

$\varphi_{c}=2.25 \frac{a_{A N}^{2.25}}{\lambda_{n}{ }^{2}}$

where $\alpha_{A N}$ is the imperfection factor.

\subsection{Comparison between fiber model and current design codes}

Figs.7-9 show the buckling strength ratios of fiber models together with design results using column curves in the three design codes, where the S460, S690 and S960 specimens are selected to present the deviations. It is found that the deviations of the two methods are clear and increase with yield strength, which means the buckling strength of HSS welded box columns are generally underestimated by the current design codes. This fact is in agreement with the existing researches and can be explained by that the influence of initial imperfection and residual stress is less severe in the HSS structures compared with the NSS structures [30-31]

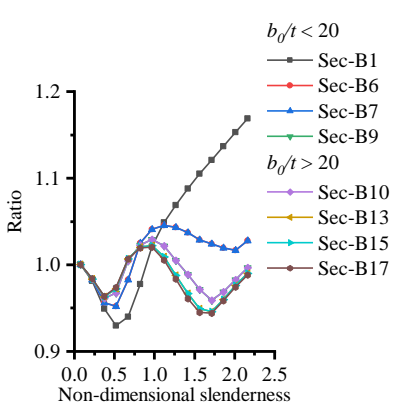

(a) GB50017-2017

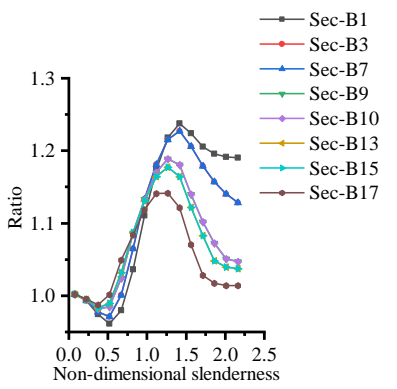

(c) ANSI/AISC 360-10

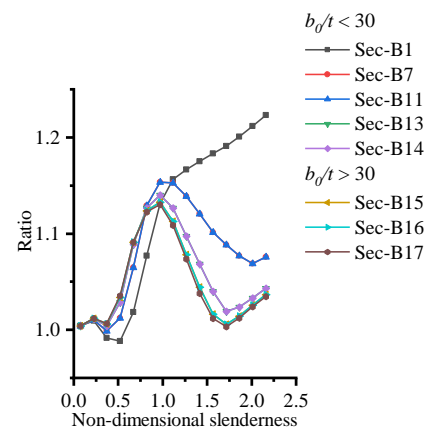

(b) Eurocode 3
Fig. 7 Comparison of fiber model results and design results for S460 specimens

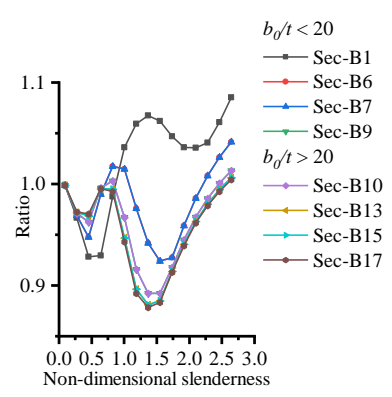

(a) GB50017-2017

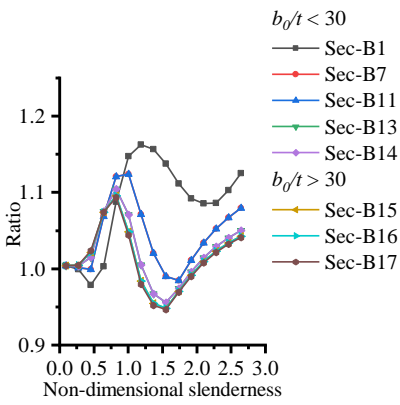

(b) Eurocode 3

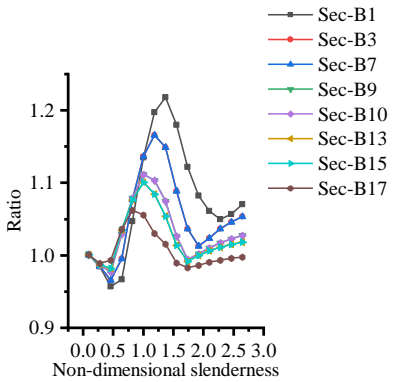

(c) ANSI/AISC 360-10

Fig. 8 Comparison of fiber model results and design results for S690 specimens

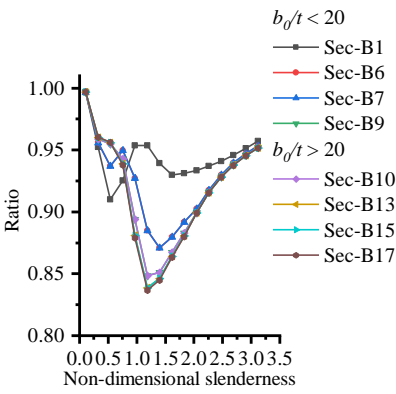

(a) GB50017-2017

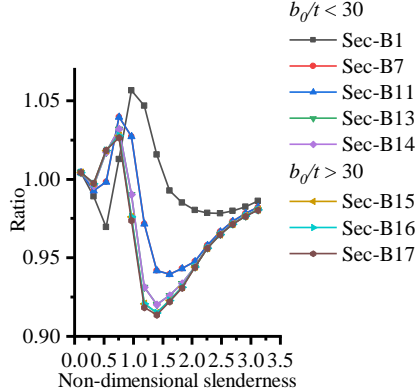

(b) Eurocode 3

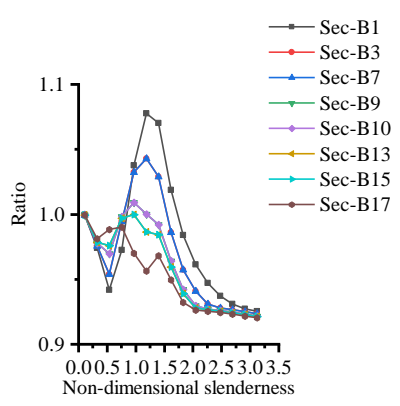

(c) ANSI/AISC 360-10
Fig. 9 Comparison of fiber model results and design results for S960 specimens

\subsection{Recommendation on column curves}

The errors between buckling strength factors using fiber models $\varphi_{F M}$ and column curves in the three design codes $\varphi_{D E}$ are calculated for all the parametric members by means of Eq. (20) and the mean errors of each steel grade are listed in Table 6.

$$
\text { Error }=\frac{\left|\varphi_{F M}-\varphi_{D E}\right|}{\varphi_{F M}} \times 100 \%
$$

It is suggested that GB50017-20017 using curve b for all the steel grades while Eurocode 3 using curve b for steel grades lower than S800 and using c for steel grades higher than S800 could make predictions with satisfactory 
accuracy to buckling strength of HSS welded box columns. Noting that if the column curve chosen according to the width to thickness ratio different from the column curve chosen according to the steel grade for one specimen, the buckling strength factor shall be the lower value obtained from the two column curves.

In the case of ANSI/AISC 360-10, it shows that most of the mean error values lie close to or lower than the recommended column curves in GB50017-2017 and Eurocode 3. And only the mean error of S460 specimens which is $7.55 \%$ lies between curve b and curve c in GB50017-2017 and slightly higher than curve $\mathrm{c}$ in Eurocode 3 . Therefore, the column curve in ANSI/AISC 360-10 is also recommended to design HSS welded box columns.

Table 6

Average errors of buckling strength between numerical results and design curves

\begin{tabular}{|c|c|c|c|c|c|c|c|}
\hline \multirow{2}{*}{ Steel grade } & \multicolumn{3}{|c|}{ GB50017-2017 } & \multicolumn{3}{|c|}{ Eurocode 3} & \multirow{2}{*}{ ANSI/AISC $360-10$} \\
\hline & Curve b & Curve $\mathrm{c}$ & Recommendation & Curve $\mathrm{b}$ & Curve $\mathrm{c}$ & Recommendation & \\
\hline S460 & $3.54 \%$ & $9.05 \%$ & Curve $b$ & $3.16 \%$ & $7.41 \%$ & Curve $b$ & $7.55 \%$ \\
\hline S550 & $3.53 \%$ & $11.84 \%$ & Curve $b$ & $3.79 \%$ & $3.61 \%$ & Curve b & $4.20 \%$ \\
\hline S690 & $3.84 \%$ & $10.52 \%$ & Curve $b$ & $3.88 \%$ & $4.61 \%$ & Curve b & $3.50 \%$ \\
\hline S800 & $5.43 \%$ & $12.80 \%$ & Curve b & $5.87 \%$ & $2.83 \%$ & Curve $\mathrm{c}$ & $3.41 \%$ \\
\hline S960 & $7.59 \%$ & $14.32 \%$ & Curve b & $8.07 \%$ & $3.36 \%$ & Curve $\mathrm{c}$ & $4.61 \%$ \\
\hline
\end{tabular}

\subsection{Proposed column curve}

In order to predict the buckling strength of HSS welded box columns with better accuracy for design, new column curves are proposed in this paper. The values of imperfection factors in the formula of column curves in Eurocode 3 $\left(a_{E}\right)$, ANSI/AISC 360-10 $\left(a_{A N}\right)$ and GB50017-2017 $\left(a_{2}, a_{3}\right)$ are obtained using non-linear regression analysis on the buckling strength factors from parametric studies. The results are demonstrated in Figs. 10-11. It is found that the imperfection factors have a significant correlation with the width to thickness ratio and the nominal yield strength. Therefore, an empirical equation related to width to thickness ratio and nominal yield strength is suggested to calculate the imperfection factors of the column curves, as shown in Eq. (21), where $a$ is the imperfection factor which is labeled as $a_{E}$ in Eurocode 3, $a_{A N}$ in ANSI/AISC 360-10 and $a_{3}$ in GB50017-2017 and $f_{y}$ is the nominal yield strength $(\mathrm{MPa})$.

$a=\left(\alpha_{1}+\alpha_{2} \frac{b_{0}}{t}\right) \times\left(\alpha_{3}+\alpha_{4} \frac{f_{y}}{460}\right)$

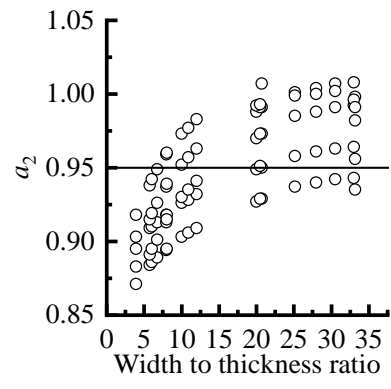

(a) $a_{2}$ of GB50017-2017

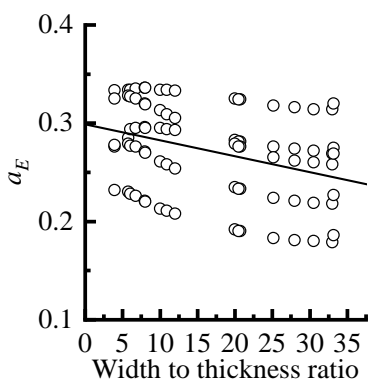

(c) $a_{E}$ of Eurocode 3

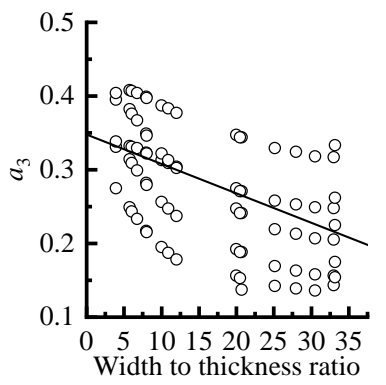

(b) $a_{3}$ of GB50017-2017

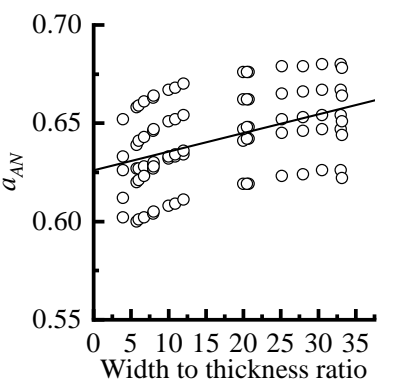

(d) $a_{A N}$ of ANSI/AISC $360-10$
Fig. 10 The relation between imperfection factor and with to thickness ratio

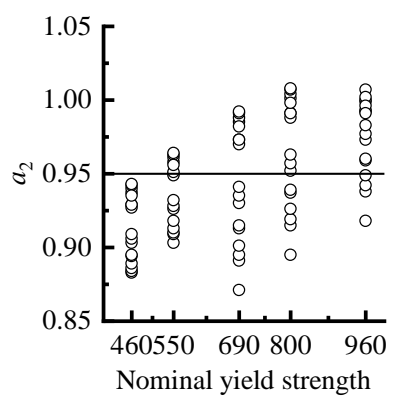

(a) $a_{2}$ of GB50017-2017

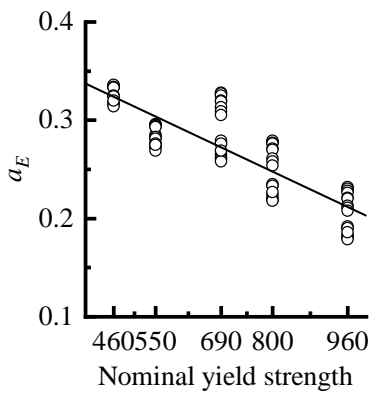

(c) $a_{E}$ of Eurocode 3

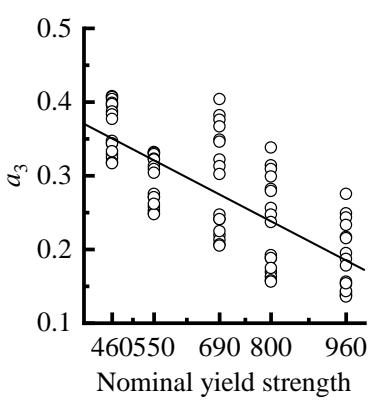

(b) $a_{3}$ of GB50017-2017

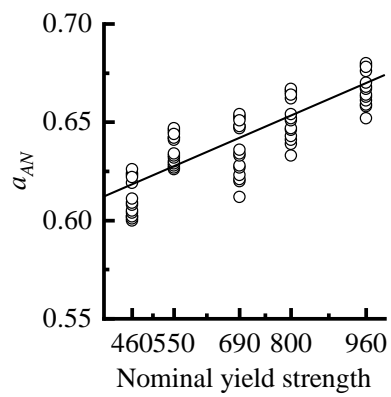

(d) $a_{A N}$ of ANSI/AISC 360-10
Fig. 11 The relation between imperfection factor and nominal yield strength

The values of regression coefficients $\alpha_{1}, \alpha_{2}, \alpha_{3}$ and $\alpha_{4}$ are listed in Table 7. For Eurocode 3 and ANSI/AISC 360-10, the imperfection factors $a_{E}$ and $a_{A N}$ can be calculated by Eq. (21). While for GB50017-2017, there are three coefficients to be determined, where the $a_{2}$ is settled as the average 0.95 , the $a_{3}$ is determined by Eq. (21) and the $a_{1}$ is computed according to the continuity condition as shown in Eq. (22).

$a_{1}=\frac{2 \times 0.215^{2}-\left(a_{2}+0.215 a_{3}+0.215^{2}\right)+\sqrt{\left(a_{2}+0.215 a_{3}+0.215^{2}\right)^{2}-4 \times 0.215^{2}}}{2 \times 0.215^{4}}$

Table 7

Values of regression coefficients

\begin{tabular}{cccccc}
\hline & & \multicolumn{5}{c}{ Regression coefficients } \\
Design code & Coefficient & $\alpha_{1}$ & $\alpha_{2}$ & $\alpha_{3}$ & $\alpha_{4}$ \\
\hline GB50017-2017 & $a_{3}$ & 2.590 & -0.032 & 0.240 & -0.071 \\
Eurocode 3 & $a_{E}$ & 1.780 & -0.009 & 0.261 & $-6.27 \times 10^{-2}$ \\
ANSI/AISC 360-10 & $a_{A N}$ & 2.820 & $4.27 \times 10^{-3}$ & 0.198 & 0.0164 \\
\hline
\end{tabular}

Fig. 12 depicts the comparison of mean errors of buckling strength factors using the recommended column curves and using the proposed column 
curves for all the parametric specimens. It can be seen that the mean error using proposed column curves are smaller than the mean error using recommended column curves given in GB50017-2017, Eurocode 3 and ANSI/AISC 360-10. Fig. 13 depicts the buckling strength factors of selected specimens obtained from fiber models together with design results obtained from proposed column curves. It can be seen that the results obtained from the proposed curves are in good agreement with the results obtained from the fiber models. Overall, it is concluded that the proposed column curves are able to make predictions with better accuracy to buckling strength factors of HSS welded box columns with different width to thickness ratios and steel grades.

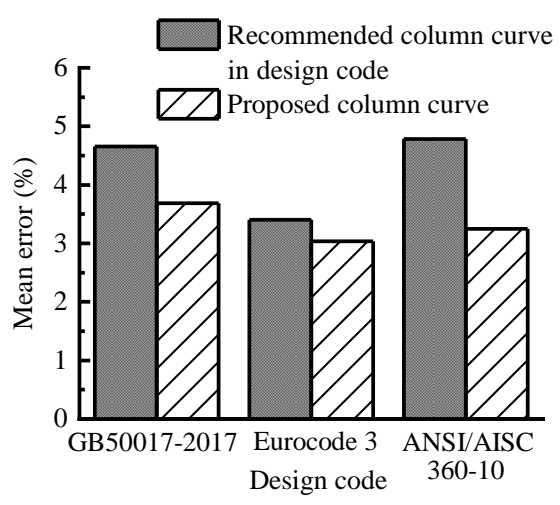

Fig. 12 Comparison of mean error between proposed column curves and design codes

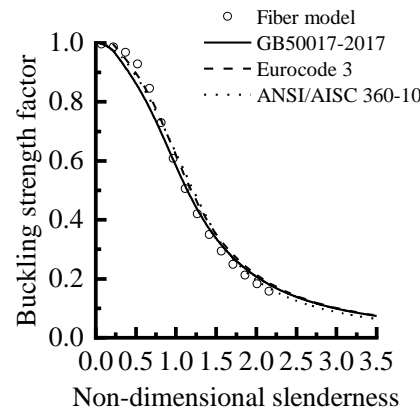

(a) S460 with Sec-B1

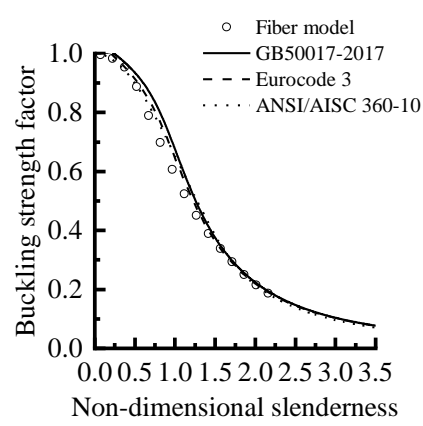

(c) S460 with Sec-B17

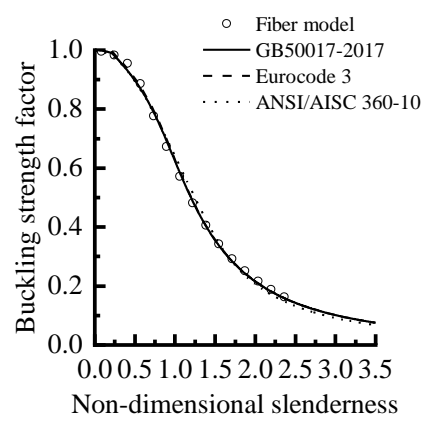

(e) S550 with Sec-B9

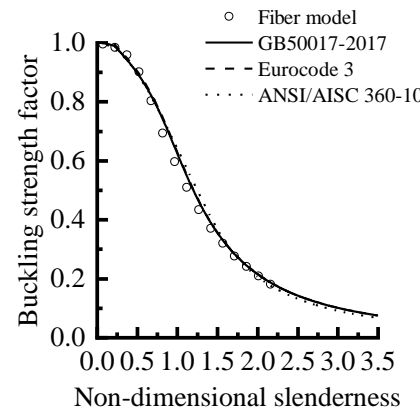

(b) S460 with Sec-B9

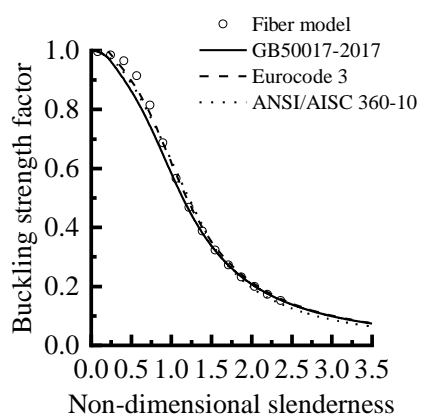

(d) S550 with Sec-B1

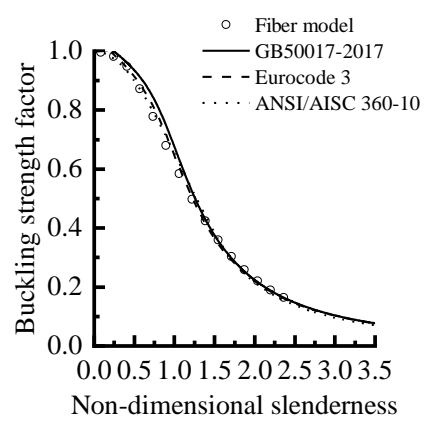

(f) S550 with Sec-B17
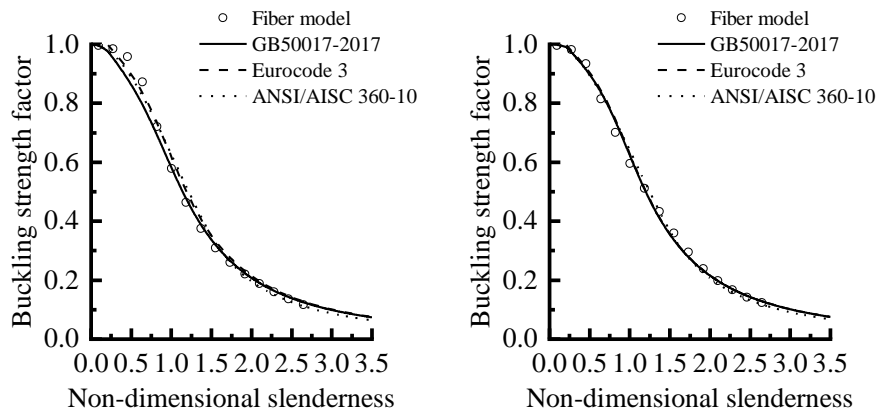

(g) S690 with Sec-B1

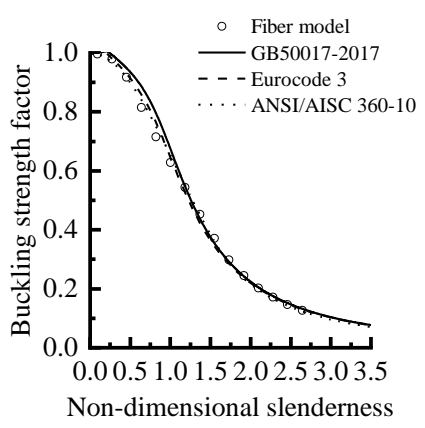

(h) S690 with Sec-B9

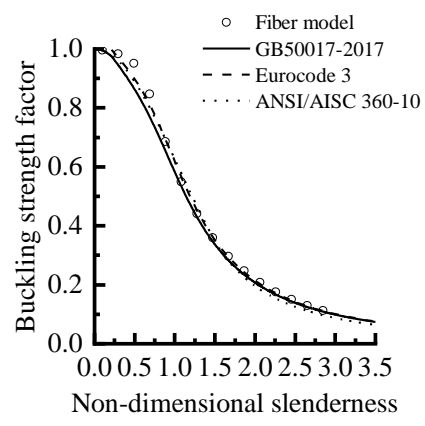

(j) S800 with Sec-B1
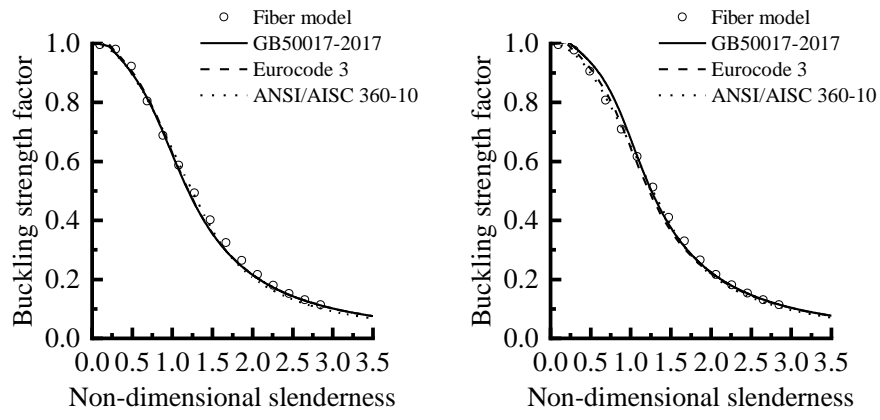

(k) S800 with Sec-B9

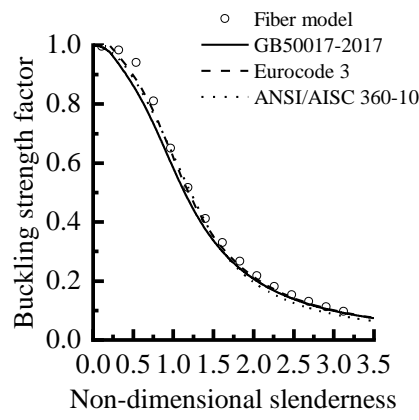

(1) S800 with Sec-B17

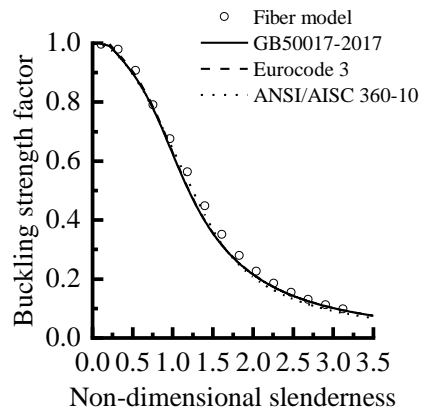

(n) S960 with Sec-B9

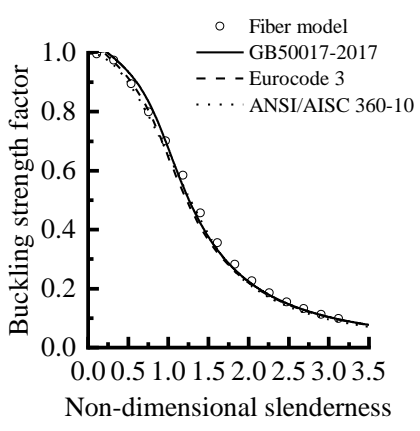

(o) S960 with Sec-B17

Fig. 13 Comparison of buckling strength factor between fiber model and proposed 


\section{Conclusion}

This paper conducted a numerical study on the buckling strength of HSS welded box columns with different steel grades under axial compression and to propose design recommendations for the current design codes. Fiber models employing unified residual stress model were established to replicate the experimental results of HSS welded box columns of different steel grades. Having the fiber models validated, parametric studies were carried out to investigate the effects of steel grade and width to thickness ratio on buckling strength of HSS welded box steel columns. The results are used to assess the applicability of current design codes including GB50017-2017, Eurocode 3 and ANSI/AISC 360-16 on buckling design of HSS welded box columns with different steel grades and sectional dimensions. The following conclusions have been made:

a)The fiber model employing unified residual stress model could accurately replicate the key test results.

b)The buckling strength factors of HSS welded box columns of different steel grades subject to axial compression from design codes GB50017-2017, Eurocode 3 and ANSI/AISC 360-10 are inconsistent with the buckling strength factors from fiber models. The average deviation of the whole parametric specimens is $8.37 \%, 4.7 \%$ and $4.6 \%$, respectively.

c)In determination of buckling strength factor of HSS welded box columns subject to axial compression, the design rules in GB50017-2017 using curve $\mathrm{b}$, the design rules in Eurocode 3 using curve $\mathrm{b}$ for steel grades lower than S800, the design rules in Eurocode 3 using curve $\mathrm{c}$ for steel grades higher than S800 and the design rules in ANSI/AISC 360-10 using single curve are recommended.

d) By updating the coefficients in the current design codes, new column curves are proposed, which takes the effects of material steel grade and sectional width to thickness ratio into consideration. The newly proposed column curves provide a unified method for the design of HSS welded box columns.

\section{Acknowledgments}

The authors are grateful to the financial support of the Natural Science Foundation of China (No.51608453)

\section{References}

[1] Nie S.D., Kang S.B., Shen L., Yang B., "Experimental and numerical study on global buckling of Q460GJ steel box columns under eccentric compression", Engineering Structures, 142, 211-222, 2017.

[2] Y B., Nie S.D., Xiong G., Hu Y., Bai J.B., Zhang W.F., Dai G.X., "Residual stresses in welded I-shaped sections fabricated from Q460GJ structural steel plates", Journal of Constructional Steel Research, 122, 261-273, 2016.

[3] Yang B., Xiong G., Ding K., Nie S.D,, Zhang W., Hu Y., and Dai G., "Experimental and numerical studies on lateral torsional buckling of welded Q460GJ structural steel beams", Engineering Structures, 126, 1-14, 2016

[4] Kang S.B., Yang B., Zhou X., Nie S.D., "Global buckling behaviour of welded Q460GJ steel box columns under axial compression", Journal of Constructional Steel Research, 140, 153-162, 2018.

[5] Zhou X, "Global Buckling Behaviour of Welded Q460GJ Steel Box Columns under Axial Compression", Licentiate Thesis, Chongqing University, Chongqing, China, 2017

[6] Ban H.Y., Shi G., Shi Y.J., "Overall buckling behavior and design method for axially compressed welded I-sectional columns constructed with different grades of high-strength steels", CHINA CIVIL ENGINEERING JOURNAL, Vol. 47 No.11, 2014

[7] Cao X., Gu L., Kong Z., Zhao G., Wang M., Kim S., Jia D. and Ma C., "Local buckling of $800 \mathrm{MPa}$ high strength steel welded T-section columns under axial compression", Engineering Structures, 194, 196-206, 2019.

[8] Yang H., Yang X.Q., Varma A.H. and Zhu Y., "Strain-Rate Effect and Constitutive Models for Q550 High-Strength Structural Steel", Journal of Materials Engineering and Performance, 28, 6626-6637, 2019.

[9] Mursi M., Uy B. "Behaviour and design of fabricated high strength steel columns subjected to biaxial bending. Part 1: Experiments", Advanced Steel Construction, 2(4), 286-313, 2006.

[10] Mursi M., Uy B., "Behaviour and design of fabricated high strength steel columns subjected to biaxial bending. Part 2: Analysis and design codes", Advanced Steel Construction, 2(4), 314-354, 2006

[11] GB 50017-2017 Code for design of steel structures, China Architecture \&Building Press, Beijing, China, 2018.

[12] BSI, Eurocode 3, Design of Steel Structures-Part 1-1: General Rules and Rules for Buildings, British Standards Institution, London, 2003.

[13] ANSI/AISC360-10, Specification for Structural Steel Buildings, American Institute of Steel Construction, Chicago, Illinois, 2010.

[14] Li D., Paradowska A., Uy B., Wang J. and Khan M., "Residual stresses of box and I-shaped columns fabricated from S960 ultra-high-strength steel", Journal of Constructional Steel Research, 166, 105904, 2020

[15] Hussain A., Liu Y.P. and Chan S.L., "Finite Element Modeling and Design of Single Angle Member Under Bi-axial Bending". Structures, 16, 373-389, 2018.

[16] Hussain A., Du Z.L., Liu Y.P. and Chan S.L., Stability design of single angle member using effective stress-strain method. Structures, 20, 298-308, 2019.

[17] Ban H.Y., Shi G., and Shi Y, "Experimental study on residual stress in 960MPa high strength steel welded box sections and unified model", CHINA CIVIL ENGINEERING JOURNAL, 46(11), 63-69, 2013
[18] Nie S.D., Zhu Q., Yang B., Li P.C., "Investigation of residual stresses in Q460GJ steel plate from medium-walled box sections" Journal of Constructional Steel Research, 148, 728-740, 2018

[19] Li T.J., Li G.Q., Wang Y.B., "Residual stress tests of welded Q690 high-strength steel boxand H-sections", Journal of Constructional Steel Research, 115, 283-289, 2015.

[20] Somodi B., Kövesdi B., "Residual stress measurements on welded square box sections using steel grades of S235-S960", Thin-Walled Structures, 123, 142-154, 2018.

[21] Wang Y.B., Li G.Q., Chen S.W., Sun F.F., "Experimental and numerical study on the behavior of axially compressed high strength steel box-columns", Engineering Structures, 58 , 79-91, 2014.

[22] Li T.J., Li G.Q., Chan S.L., Wang Y.B., "Behavior of Q690 high-strength steel columns: Part 1: Experimental investigation", Journal of Constructional Steel Research, 123, 18-30, 2016.

[23] Li T.J., Liu S.W., Li G.Q., Chan S.L., Wang Y.B., "Behavior of Q690 high-strength stee columns: Part 2: Parametric study and design recommendations", Journal of Constructional Steel Research, 122, 379-394, 2016.

[24] Ban H.Y., Shi G., Shi Y.J., Wang Y.Q., "Overall buckling behavior of 460 MPa high strengt steel columns: Experimental investigation and design method", Journal of Constructional Steel Research, 74, 140-150,2012.

[25] Xue, J.Y, "Experimental Research on the Overall Buckling Behavior of High Strength Steel Members under Compression", Licentiate Thesis, Southeast University, NanJing. China., 2014

[26] Cuong N.H., Kim S.E., Oh J.R., "Nonlinear analysis of space steel frames using fiber plastic hinge concept", Engineering Structures, 29, 649-657, 2007.

[27] $\mathrm{Li}, \mathrm{T}$., Liu, S. and Chan, S. "Cross-sectional analysis of arbitrary sections allowing for residual stresses", Steel and composite structures, 18(4), 985-1000, 2015

[28] Ban H.Y., Shi G., Shi Y.J., Wang Y.Q., "Residual stress of $460 \mathrm{MPa}$ high strength steet welded box section: Experimental investigation and modeling", 64, 73-82, 2013.

[29] Khan M., Paradowska A., Uy B., Mashiri F., Tao Z., "Residual stresses in high strength stee welded box sections", 116, 55-64, 2016.

[30] Fang H. and Chan T., "Buckling resistance of welded high-strength-steel box-section members under combined compression and bending", Journal of Constructional Steel Research, 162105711,2019

[31] Han H., Chan T.M., "Buckling resistance of welded high-strength-steel box-section member under combined compression and bending", Journal of Constructional Steel Research, 162, $150711,2019$. 